\title{
Implementation of blood safety legislation in Azad Jammu and Kashmir, Pakistan
}

\begin{abstract}
Pakistan's blood transfusion system is regulated by federal and provincial legislation, adopted since 1997. The Azad Jammu and Kashmir (AJK) is one of the autonomously administered territories of Pakistan. The AJK's blood safety act came out in 2003, to regulate the blood transfusion services but remained ineffective for the next decade due to no implementation. During the period 2014-2017, the AJK government sought technical assistance from the Islamabad Blood Transfusion Authority and initiated the implementation of blood safety legislation in the state of AJK through the AJK Blood Transfusion Authority. The AJK BTA identified and inspected 64 blood banks with a total annual blood collection of 30,833 . The majority $(75 \%)$ of the blood banks were in $\mathrm{NGO}$ /private sector while the remaining $25 \%$ belonged to the public sector. Only six blood banks fulfilled the minimum criteria of licensing set by the AJK BTA. As a result of this ground-breaking work, the AJK became the second region of the country (after Islamabad Capital Territory) to have completed a mapping and inspection exercise in the entire State. This will go a long way in the consolidation of blood transfusion services in AJK.
\end{abstract}

Keywords: blood, regulation, ajk, Pakistan, legislation
Volume 8 Issue 4 - 2020

\author{
Usman Waheed,' Naveed Ahmed, ${ }^{2}$ Wafa \\ Hussain, ${ }^{2}$ Akhlaaq Wazeer, ${ }^{2}$ Noor e Saba, ${ }^{3}$ \\ Zahida Qasim, ${ }^{2}$ Hasan Abbas Zaheer' \\ 'Islamabad Blood Transfusion Authority, Ministry of National \\ Health Services, Government of Pakistan \\ ${ }^{2} \mathrm{AJK}$ Blood Transfusion Authority, Department of Health, \\ Government of Azad Jammu \& Kashmir, Pakistan \\ ${ }^{3}$ Khyber Pakhtunkhwa Blood Transfusion Authority, Department \\ of Health, Government of Khyber Pakhtunkhwa, Pakistan
}

Correspondence: Usman Waheed, Ph.D. Islamabad Blood Transfusion Authority, Ministry of National Health Services, Islamabad, Pakistan, Email usman.waheed07@gmail.com

Received: July 08, 2020 | Published: August 19, 2020

\section{Introduction}

The Azad Jammu and Kashmir (AJK) is one of the autonomously administered territories of Pakistan. It is positioned in the northeast of the federal capital, Islamabad. Since 1975, the state of Azad Jammu and Kashmir is governed under the Parliamentary democracy system. Administratively, AJK is divided into multiple levels of administrative units including three divisions, 10 districts, and 32 tehsils, each covering a particular geographical jurisdiction. According to the 2017 census, the total population of AJK was 4.04 million. The blood transfusion services (BTS) are a fundamental component of the AJK government's Health Policy. The blood transfusion services are supplied by hospital-based blood banks both in the public and private sectors. Some NGO sector blood banks are also operational which mostly cater to the thalassaemia major patients. The feeblest link identified in the blood transfusion services of AJK has been inadequate regulation and monitoring. To address this deficiency, the Government of AJK enacted a 'Blood Safety Act' in the year $2003^{1}$ to regularize the blood transfusion system in the state through a Blood Transfusion Authority (BTA). However, practically, the legislation largely remained unimplemented mainly due to the de-prioritization of the blood transfusion system in the overall healthcare system, a lack of technical expertise, and the allocation of resources.

The role of regulation in ensuring the quality and safety of blood supply and transfusion systems has been recognized by the World Health Organization (WHO) since 1975. ${ }^{2}$ The WHO has been at the forefront to encourage the member countries to develop national blood service centred on voluntary non-remunerated blood donation (VNRBD), and enact effective legislation to steer the operations of a blood service. The blood regulatory system deals with legislation, regulations, policies while the blood supply system is responsible for product liability, i.e. blood. Cognizant of the international resolutions, the Pakistan government took concrete and positive steps in establishing and strengthening the blood regulation to improve the blood safety standards throughout the country.
Through the Pak-German cooperation project phase I (2010-16), a blood system reform was instigated and institutionalized by the building of new infrastructure of regional blood centres and hospital blood banks across the country following international standards. ${ }^{3}$ In AJK, it included the construction of a state of the art Regional Blood Centre and renovation and refurbishment of six attached hospital blood banks in the capital city - Muzaffarabad. The nationwide reform agenda also comprised of strengthening and capacity development of the blood regulatory authorities including the AJK Blood Transfusion Authority (BTA) notified under section 5 of the AJK Blood Safety Act, 2003. The functions of the AJK Authority as per legislation are shown in Figure 1.

As a result of the efforts made at the national level, the AJK BTA was made functional and initiated the implementation of the regulatory framework of blood transfusion services. For the technical supervision, the Authority communicated with the Ministry of National Health Services which had a successful experience of regulation in the federal capital through the Islamabad Blood Transfusion Authority. ${ }^{4}$ The Islamabad Blood Transfusion Authority (IBTA) provided training and orientation to the AJK BTA team on its pre-tested technical and inspection tools (e.g. inspection checklist, national standards, national quality control guidelines, a field manual for inspectors, and functional brief for blood transfusion authorities). The IBTA also guided in the design and later conduction of blood bank inspections in all three divisions (10 districts) of Azad Jammu and Kashmir. As a first step, announcements were made in the print and electronic media for registration of blood banks. However, only one blood bank applied for registration to AJK BTA. The Authority then conducted a rapid mapping exercise through snowball sampling and identified 64 potential blood banks operating in the state of AJK. The number of blood banks identified was comparatively high when compared with the earlier expected figure highlighting the lack of regulatory oversight.

As the topography of AJK is mostly hilly and mountainous, with heavy snowfall in winters and heavy rains during monsoon season, 
it poses a challenge to the overall health services including the monitoring and inspection of blood banks. The commute is often difficult due to the security situation along the Line of Control (LoC). Moreover, the 10 districts of AJK are in the shape of a long C-shaped geographical region resulting in long distances to be covered for inspections. Considering these challenges, the inspections were conducted in an organized and systematic manner from 2017 through 2018. The 10 districts were covered in three inspection phases as stated below:

Phase 1 Districts: Bhimber, Mirpur, Kotli, and Sudhanoti (Pallandri)
Phase II Districts: Hattian Bala (Jhelum Valley), Muzaffarabad, and Neelum Valley

Phase III Districts: Bagh, Poonch (Rawalakot), and Haveli (Forward Kahuta)

The total number of annual donations (for the year 2017) in the inspected 64 blood banks was 30,833 mostly from family replacement donors $(84.26 \%)$. Sixteen blood banks $(25 \%)$ belonged to the public sector while $48(75 \%)$ were in the private/NGO sector managed through philanthropic donations. District Kotli had the highest number of blood banks with 21 followed by 16 in District Mirpur.

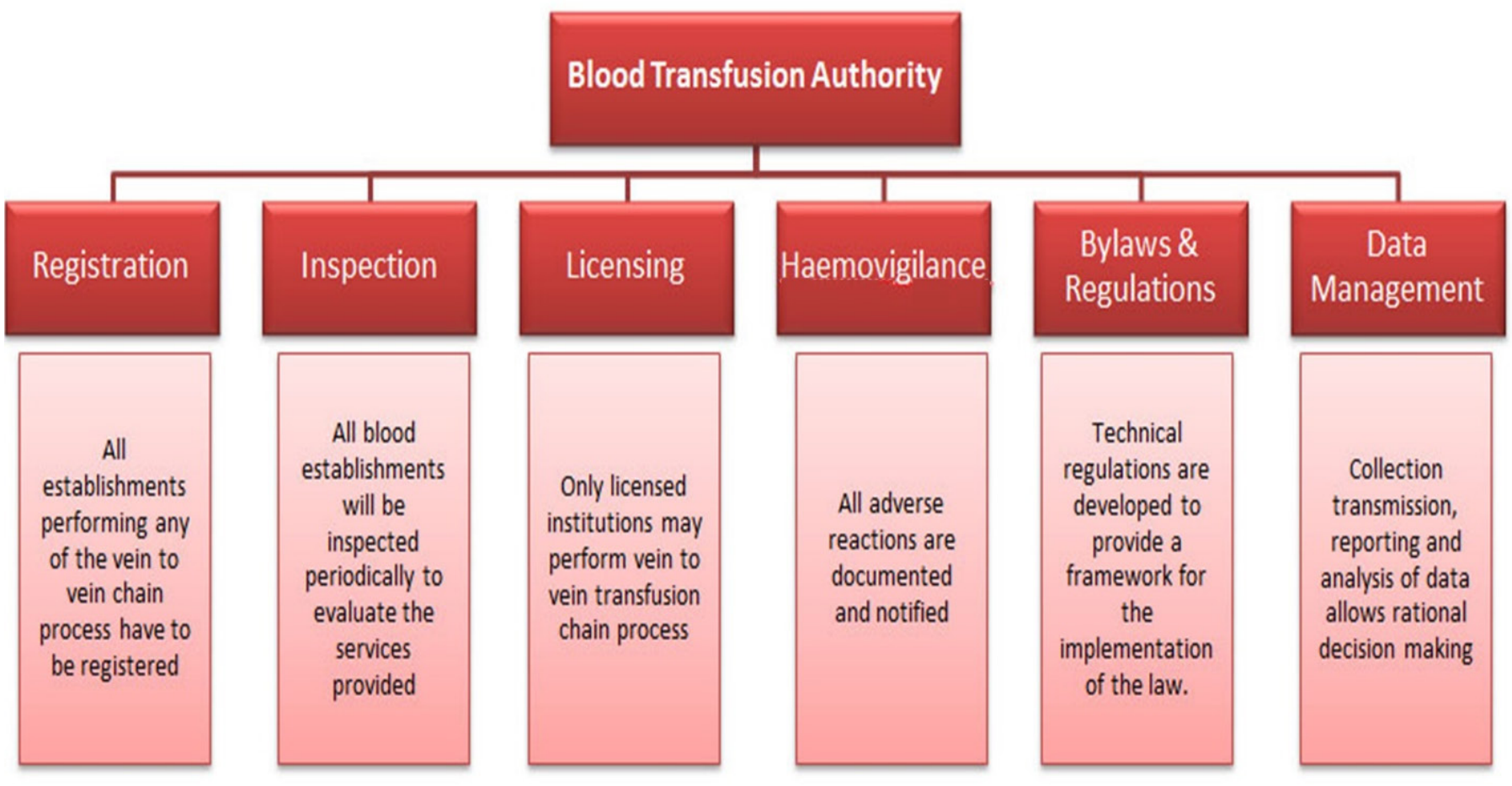

Figure I Functions of AJK Blood Transfusion Authority

The number of donations in these blood banks ranged from 16 to 5,621 per year indicating considerable variations and limited workload in the majority of the centres (Table 1). This disproportionate burden of work strongly supports the concept of the centralization model of blood transfusion services which is being implemented in the country through the Pak-German cooperation project - the Safe Blood Transfusion Programme (SBTP). According to the legislation, the blood banks cannot be closed down due to inadequate workload. But with the emergence of modern Regional Blood Centres through the SBTP, the unsustainable and unsafe smaller blood banks would eventually fade out.

On the whole, the quality of service delivery in the inspected blood banks was found to be poor. Except for six blood banks, none of the blood banks were manned by qualified pathologists or even a medical officer. The private/NGO sector blood banks were mostly managed by laboratory technicians who were remotely acquainted with the basic concepts of blood banking.
The practices in most of the visited blood banks were primitive, unsafe, and of poor quality. The staff capacity was weak although their numbers were sufficient to cater to the existing little workload. The blood donation area was not clean, comfortable, well-lit, or spacious with no privacy for the donor except for Regional Blood Centre in Muzaffarabad and the Divisional Headquarters Teaching Hospital Blood Bank in Mirpur. The behavioral screening, history, physical examination, and haemoglobin testing of the donors were performed only in three centres. Blood grouping was done on tiles/slides in all centres visited. The concepts of quality control and haemovigilance were nonexistent. Due attention is not paid to documentation and the data management methodology is mostly manual on registers and only two blood banks have a computer-based data management. The screening for transfusion-transmitted infections was performed via RDTs (rapid diagnostics tests) in all blood banks except for the Muzaffarabad Regional Blood Centre which is equipped with fully automated chemiluminescence immunoassay (CLIA) and an enzymelinked immunosorbent assay (ELISA) analyzers. 
Table I Number of blood banks with annual blood collection in the state of AJK (in 2017)

\begin{tabular}{lll}
\hline District & $\begin{array}{l}\text { Blood banks } \\
(\mathbf{n})\end{array}$ & $\begin{array}{l}\text { Annual donations } \\
(\mathbf{2 0 1 7})\end{array}$ \\
\hline Muzaffarabad & 7 & 10,582 \\
Neelum Valley & 3 & 92 \\
Hattian Bala & 2 & 52 \\
Bagh & 6 & 1,129 \\
Poonch & 1 & 2,925 \\
Haveli & 2 & 29 \\
Sudhnoti & 2 & 1,472 \\
Bhimber & 4 & 906 \\
Mirpur & 16 & 10,103 \\
Kotli & 21 & 3,543 \\
Total & 64 & 30,833 \\
\hline
\end{tabular}

Of the 64 blood banks inspected by the Authority, only six blood banks were issued licenses for a period of one year after fulfilling the minimum standards and criteria. Five centres from the mapped blood banks were not functioning at the time of inspection including one from the public sector and were directed to coordinate with AJK BTA before initiating operations. The BTA sealed one blood bank on spot due to critical non-compliance (failed to provide any evidence of cross-matching and screening for transfusion-transmitted infections). The remaining 52 blood banks with significant non-compliance were placed on a 3-month probation after informing them about all noncompliances through an inspection report. They will be re-inspected by the Authority after the probation period.

\section{Conclusion}

As a result of this ground-breaking effort, the AJK became the second region of the country (after Islamabad Capital Territory) to have completed a mapping and inspection exercise in the entire State. The AJK BTA formulated a detailed inspection report and submitted it to the Director-General Health, AJK. The Report included recommendations that provide a roadmap for improving the blood safety standards in AJK. Besides, full operationalization of the German government-funded Regional Blood Centre in District Muzaffarabad and the development of a similar Centre in District Mirpur by December 2020 will go a long way in the consolidation of transfusion services in AJK and the justification of the existence of many smaller blood banks will cease.

\section{Acknowledgments}

None.

\section{Conflicts of interest}

The authors declare that they have no conflicts of interest.

\section{References}

1. Azad Jammu and Kashmir Transfusion of Safe Blood Act XVI of 2003, No. ID/645-52/03. Law, Justice, Human Rights, and \& Parliamentary Affairs Department.

2. World Health Organization (WHO). Utilization and supply of human blood and blood products (WHA 28.72). 28 ${ }^{\text {th }}$ World Health Assembly, 1975.

3. Zaheer HA, Waheed U. Blood safety system reforms in Pakistan. Blood Trans. 2014;12(4):452-457.

4. Zaheer HA, Waheed U. Impact of regulation of blood transfusion services in Islamabad, Pakistan. Glob J Transfus Med. 2016;1(1):29-31.

5. Waheed U, Hasan SI, Wazeer A, et al. The status of blood safety in Islamabad, Pakistan. Ann Pak Inst Med Sci. 2016;12(4):209-214. 